
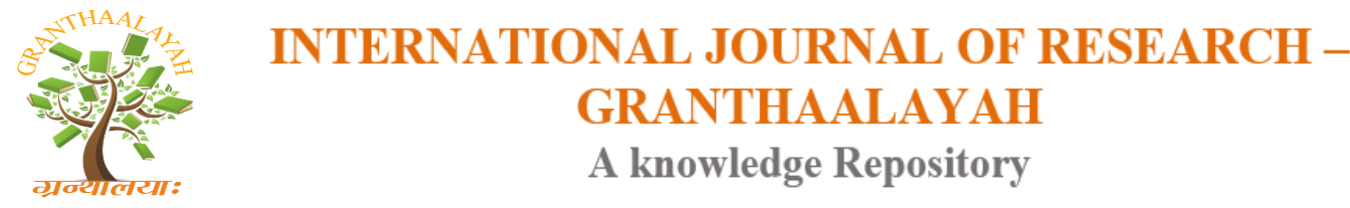

Science

\title{
A REVIEW OF EXPERIMENTAL STUDY AND PERFORMANCE OF FLAT PLATE SOLAR WATER HEATER WITH DIFFERENT FLOW RATES
}

\author{
Shiv Kumar Tripathi ${ }^{* 1}$, Prof. Mohammad Azim Aijaz ${ }^{2}$ \\ ${ }^{* 1}$ M.Tech. Scholar, Department of Mechanical Engineering, Trinity Institute of Technology \& \\ Research, Bhopal (M.P.), INDIA \\ ${ }^{2}$ Assistant Professor, Department of Mechanical Engineering, Trinity Institute of Technology \& \\ Research, Bhopal (M.P.), INDIA
}

DOI: https://doi.org/10.29121/granthaalayah.v4.i11.2016.2427

\section{ABSTRACT}

The analysis of thermal performance of the flat-plate collector includes parameters such as solar intensity, ambient temperature and configuration of flat-plate collectors etc. A Solar Water Heater are devices which are provides hot water for bathing, washing, cleaning, etc. using of solar energy. It is generally installed where sunlight are available. The solar energy is the most capable of the alternative energy sources. Solar energy is considered an attractive source of renewable energy that can be used for water hearing in both homes and industry.

Keywords:

Solar water heater, flat plate solar collector, different flow rates.

Cite This Article: Shiv Kumar Tripathi, and Prof. Mohammad Azim Aijaz, "A REVIEW OF EXPERIMENTAL STUDY AND PERFORMANCE OF FLAT PLATE SOLAR WATER HEATER WITH DIFFERENT FLOW RATES" International Journal of Research Granthaalayah, Vol. 4, No. 11 (2016): 108-110.

\section{INTRODUCTION}

Solar collectors are widely used for process heat, space heating and/or producing domestic hot water by solar energy. It is recognized in many countries that the large scale application of this clean and environmentally safe solar technology decreases significantly the use of fossil energy resources and the impact on the environment. Therefore, the propagation of the solar collectors has become one of the main points of the energy policy in many countries.

For water-heating the most practical collectors are the flat-plate collectors which consist of a transparent glazing, preferably $4 \mathrm{~mm}$ thick glass pane of low iron content; a metal absorber, generally a $0.5-2.0 \mathrm{~mm}$ thick copper plate in metallic contact with the metal tubes that transport 
the heat exchange fluid, and proper insulation made by inexpensive insulation materials to decrease back and edge losses.

The heat exchanging medium enters the collector from below and exits the collector at its upper extremity. Therefore, the transportation of the fluid is mainly based on auto circulation, but in most cases liquid pumps are also used.

\section{FLAT-PLATE COLLECTORS}

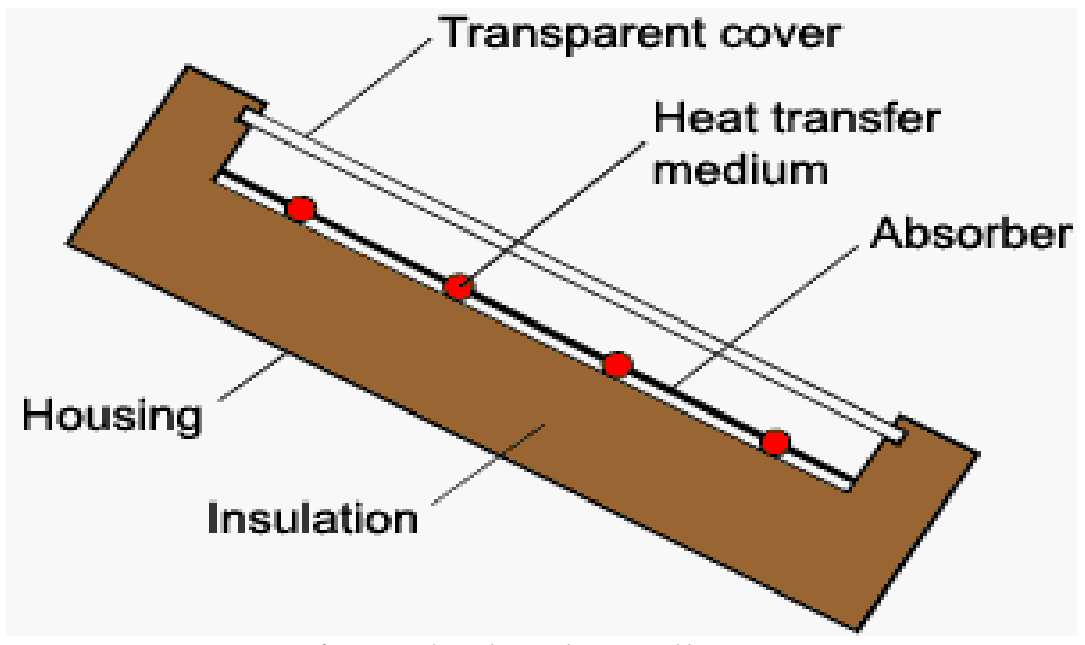

Figure 1: Flat-plate collectors

\section{SELECTIVE ABSORBERS}

Black materials absorb sunlight very well, and heat up as a result. Since metallic materials do not naturally have a black surface, they need to be coated for selective absorption.

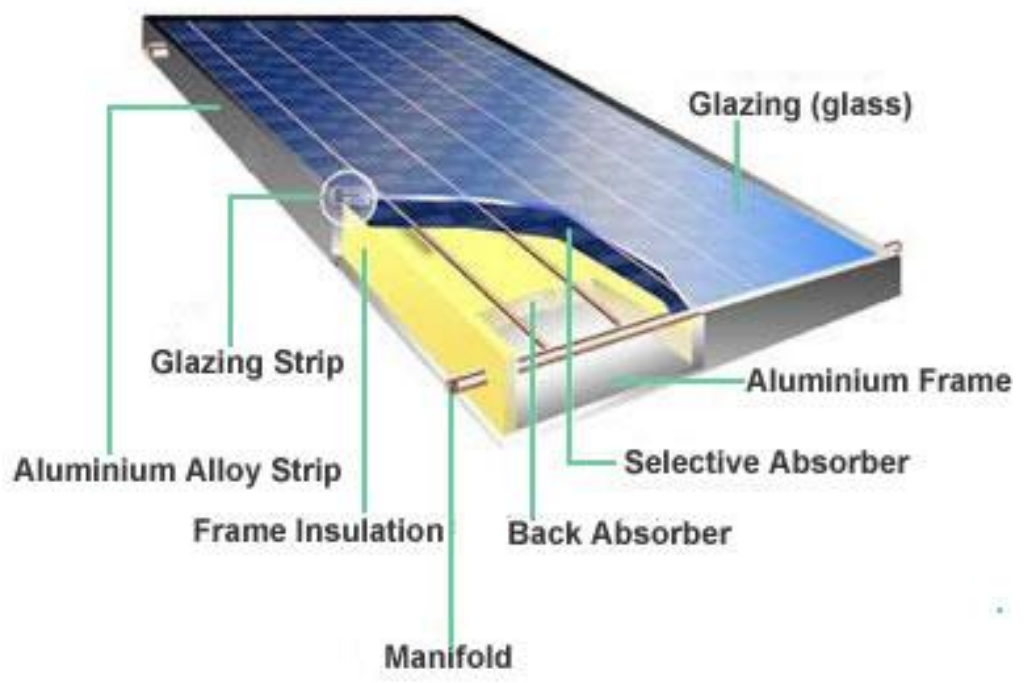

Figure 2: Flat-plate collectors with absorbers 


\section{SYSTEM DESIGN REQUIREMENTS}

The type, complexity, and size of a solar water heating system is mostly determined by:

- Changes in ambient temperature and solar radiation between summer and winter.

- The changes in ambient temperature during the day-night cycle.

- The possibility of the potable water or collector fluid overheating.

\section{FREEZE PROTECTION}

In some direct systems, the collectors can be manually drained when freezing is expected. This approach is common in climates where freezing temperatures do not occur often, but is somewhat unreliable since the operator can forget to drain the system. Other direct systems use freeze-tolerant collectors made with flexible polymers such as silicone rubber.

\section{EVACUATED-TUBE COLLECTORS}

Convection heat loss due to air movements inside the collector can be significantly reduced by maintaining a vacuum between the front cover and the absorber of a flat plate collector. As the ambient air pressure would then force the front cover against the absorber, small supports must be used between the back of the collector and the cover, to keep the cover itself in shape.

The high (almost complete) vacuum inside the closed glass tube of the evacuated-tube collector is more stable over a long period of time than in an evacuated flat-plate collector. Due to their shape, glass tubes can better resist the ambient air pressure, and therefore no supports are needed between the back and front sides.

\section{REFERENCES}

[1] Azad E. Theoretical and experimental investigation of heat pipe solar collector. Experimental Thermal and Fluid Science, 2008, 32(8): 1666-1672.

[2] Duffie JA, Beckman WA, "Solar Engineering of Thermal Process", Wiley, Inc. New York, 1991.

[3] Kaygusuz K, Comaklio Ayhan T., "Solar-assisted heat pump systems and energy storage”, Solar Energy, 47 (1), 1991, 383-391.

[4] Chaturvedi SK, Chiang YF, Roberts AS, "Analysis of two-phase flow solar collectors with application to heat pumps”, Journal of Solar Energy Engineering, 104 (1), 1982, 358-365.

[5] Morgan RG, "Solar assisted heat pump”, Solar Energy, 28(1), 1982, 129-135.

[6] O'Dell MP, Mitchell JW, Beckman WA., "Design method and performance of heat pumps with refrigerant- filled solar collectors", Journal of Solar Energy Engineering, Transaction of the ASME, 106 (1), 1984, 159-164. 